\title{
HISTORICAL AND EDUCATIONAL ASPECTS OF DISCOVERIES AND INVENTIONS THAT REVOLUTIONIZED MANKIND
}

\author{
Adrian IOANA ${ }^{1, *}$, Daniela TUFEANU ${ }^{1}$, Dragos Florin MARCU ${ }^{1}$, Bogdan FLOREA ${ }^{1}$, Daniela \\ Alice LUTA ${ }^{1}$, Bianca Cezarina ENE ${ }^{1}$, Daniela Ionela JUGANARU ${ }^{1}$, Roxana Marina SOLEA ${ }^{1}$ \\ ${ }^{1}$ University Politehnica of Bucharest, Faculty Science and Engineering Materials, \\ Bucharest, Spl. Independentei 313, 060442, Romania
}

\begin{abstract}
This article presents discoveries and inventions from different periods of mankind, which played an important role in social and technological evolution. Thus, from the period of the Ancient World (prehistory - $400 \mathrm{AD}$ ), we present: the appearance of stone tools (which occurred in East Africa and belongs to the first hominids); pottery (appeared in $10500 \mathrm{BC}$ ); the development of metallurgy (began in the Middle East, around $6500 \mathrm{BC}$ ); the invention of the ox-drawn plow (which occurred around 4000 BC); the construction of the first pyramid in Egypt (2600 BC); the development of iron processing (as part of the development of metallurgy, it occurred around 1400 BC); modernization of papermaking technology (attributed to Tsai Lun, China, around 105 $A D)$; Another historical period that we analyzed in terms of discoveries and innovations that revolutionized humanity was the Middle Ages (400 - 1500). Thus, from this period we presented the following discoveries and inventions: the discovery of the number zero (occurred in 520 and belongs to Indian mathematicians); woodcut printing (appeared in sixth century China); the first printed newspaper (year 700); the development of algebra (it belongs to the Greek mathematician Diophantos, 3rd century AD); gunpowder (it was discovered around 850); the establishment of the University of Bologna (made in 1088); The last period approached was the current one. From this period we presented the following discoveries: magnetism - a new form of electricity; devices controlled only by hand gestures.
\end{abstract}

Keywords: discoveries, inventions, materials, historical periods, human revolution.

\section{Introduction}

The importance of knowledge in the field of invention is obvious. From this point of view, a thorough documentary study on the evolution and impact of discoveries and inventions in society is absolutely necessary.

In fact, it is a professional obligation of any inventor that, after having an innovative idea, the first stage for the elaboration of that invention to be a very rigorous documentary study in the approached field. He must ensure that his idea is not already patented, in which case his work would be in vain.

The educational aspect within this process of knowledge in the field of invention has consequently a perfect importance. In this way, in addition to ensuring the necessary (and not sufficient) factors for the design and realization with professionalism of some patent application files, the transfer of interest in inventions to future generations is also ensured [1-3]. 


\section{Discoveries in the Ancient World (prehistory - 400 AD)}

Since the advent of life (the emergence of the first simple chains of C-based compounds), discoveries (and later inventions) have played a special role in the evolution of mankind.

The appearance of stone tools occurred in East Africa and belongs to the first hominids. This appearance is rightly considered the first manifestation of cultural behavior in human history. In the year $15000 \mathrm{BC}$. the bow and arrows were invented. This invention represents an important technological advance and allowed the first hunters to benefit from accuracy and superior speed in action [3-5].

Ceramics appeared in $10500 \mathrm{BC}$. The discovery belongs to a population of hunters and fishermen from the first Jamon period, from the islands of Japan.

The development of metallurgy began in the Middle East, around $6500 \mathrm{BC}$. After the process of burning (baking) clay vessels in furnaces, the same furnaces were used to melt copper. The first such processing was performed by craftsmen from Catal Hoyuk and Mesopotamian cities. Copper is processed to make beads and other decorative objects. Then, around $4000 \mathrm{BC}$, it was discovered that in others with tin $(\mathrm{Sn})$, copper could produce a more resistant one, bronze.

The invention of the ox plow, which took place around $4000 \mathrm{BC}$, resulted in the release of an important part of the human labor force from agriculture.

The plow brought the advantage of plowing the land in a "mechanized" system and thus opened new horizons for agriculture. The immediate results of the plow inventory were: abundant harvests; the progress of human civilization.

The construction of the first pyramid in Egypt dates back to $2600 \mathrm{BC}$. It is also attributed to Doctor Imhotep, an architect, artist and engineer. It happened during the reign of Pharaoh Djoser (2630-2611 BC).

Imhotep's pyramid was $65 \mathrm{~m}$ high, was built in steps and was the first in the world made only of quarry stone and was built in the first grandiose royal tomb of ancient Egypt.

The development of iron processing, as part of the development of metallurgy, took place around $1400 \mathrm{BC}$. This development has led to important developments in agriculture and beyond. Cast iron was produced in Asia Minor as early as 200 BC. However, it was not until around 1400 BC. the Hittites managed to produce wrought iron.

The technology then spread to Europe and India, around $100 \mathrm{BC}$, after which it appeared in Africa (900 BC) and China (700 BC).

The development of medical techniques took place in $400 \mathrm{BC}$, when the Indian surgeon Susruta developed methods for operating on: cataracts, kidney stones, rhinoplasty.

All of Susruta's exceptional achievements were collected in the work "Suscruta Samhita", also called the Suscruta Compendium.

The modernization of papermaking technology is attributed to Tsai Lun, China, around $105 \mathrm{AD}$. He made his paper by crushing and moistening some hemp remnants, mixed with old clothes, mulberry bark and fishing tackle. Then pressed this paste in the form of a sheet, on which, after drying, the ink could be applied.

The use of paper spread rapidly in China, but in Europe it arrived much later, in the eighth century, on the silk road.

\section{Discoveries and inventions from the Middle Ages (400 - 1500)}

The discovery of the number zero occurred in 520 and belongs to Indian mathematicians (Gupta dynasty in northern India). Older numbering systems, for thousands of years, started counting from the number 1 . Around the year 500, the mathematician Aryabhata described the number zero as a quantity. Then, in the following centuries, mathematicians formulated laws regarding the mathematical operations of: addition, subtraction and multiplication with "nothing". 
The wood press appeared in sixth-century China (593) and was invented by a Buddhist craftsman. This pattern appeared as a cheaper and easier method of reproducing the holy scriptures. The printing process was as simple as it was revolutionary. The text and images were applied (printed) on a sheet of paper made of rice, by pressing with a wooden plate on which were carved in relief the respective letters and images.

The first decimal calculus was invented by Indian mathematicians, disciples of Aryabhate, the mathematician who by the year 500 had discovered the number zero. They, the disciples of Aryabhate, invented the decimal numerical system, which worked on the basis of 10 , using numbers from 0 to 10 . This numerical system first appeared on a tablet called "Gurjara Inscription", around 595 AD.

The first printed newspaper (700) was due to the rising Tang Empire. Tang officials have resorted to an old tradition of the Han dynasty, that of circulating newsletters called "tipao". These sheets were distributed among officials and officials in order to inform them about the business in the yard. In a short time, this "tipao" was produced by printing it using the wooden press described above (printing with the wooden press)

The development of algebra belongs to the Greek mathematician Diophantos (3rd century AD) who solved unknown quantities using a given set of known conditions (later algebraic equations). Another mathematician, Al-Khwarizmi, later extended the work of Diophantos. AlKhwarizmi presented the problems in two ways: first with words and then with geometric diagrams (the later graphical method of solving).

Gunpowder was discovered about 850, by chance, by the alchemists of the Tang dynasty. The incident by which the gunpowder was discovered was based on the concerns of these alchemists in the field of immortality. In this sense, they combined, in various proportions, 3 substances: sulfur, saltpetre and coal. Paradoxically, instead of approaching immortality, they invented something that did much harm to mankind.

The University of Bologna was founded in 1088, given that European states were distancing themselves from the papacy in Rome. It is the oldest university in the world. The emergence of the University of Bologna was due to the need of young people at that time to study civil law and thus prepare for leadership positions in governments. The University of Bologna had famous graduates, such as: Dante Alighieri; Francesco Petrarca; Polish astronomer Nicolaus Copernicus and many others. A recognition of the value and tradition of the University of Bologna is the adoption of the "Bologna Program" in the field of higher education throughout Europe.

\section{Discoveries and inventions from the current period}

\section{Magnetricity - a new form of electricity}

Researchers at the London Center for Nanotechnology, Oxford, have made the first demonstration of the existence of a magnetic version of electricity, called magnetism. Unit magnetic charges behave like electrical charges. One-pole magnets contain special crystals, called "spin ice," which generate a "magnetic current." The phenomenon is known as "magnetism". Researchers have shown that one-pole magnets have "particles" that carry the magnetic charge, but they only exist in "spin ice" crystals [6,7].

Professor Steve Bramwell, together with the group of researchers he coordinated, conducted a study on the magnetic monopolies of dysprosium titanate crystals. The study led to the identification and separation of unique magnetic charges that interact exactly like electric ones, thus being able to generate magnetic current. It is about a theorized behavior for almost 70 years, but it has not been highlighted in practice.

In Fig. 1 we schematically present the mechanism of magnetism formation. 


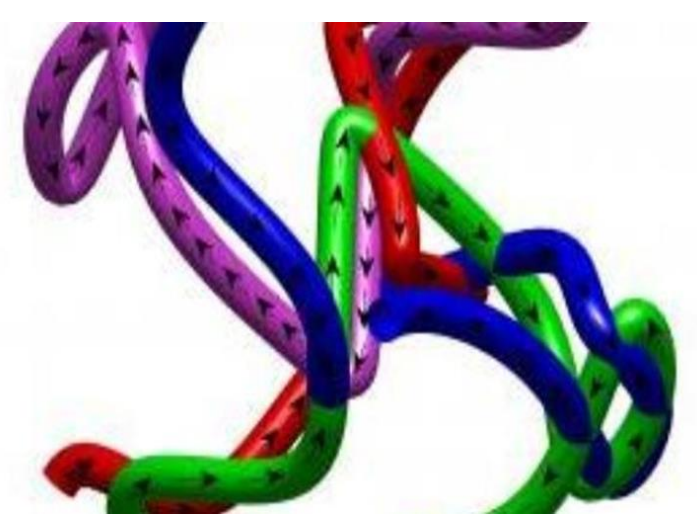

Fig. 1. Magnetism formation scheme; Source: Corriere della Sera

To prove the existence of magnetic current, researchers explored the 1934 theory of Lars Onsager (Norwegian Nobel Prize-winning physicist and chemist) on the motion of ions in water through a material that has the property called "spin ice". (allows a non-zero residual entropy). They tested the theory by applying a magnetic field to a sample of "spin ice" material in very low temperature conditions and following the process with the help of muons. Professor Bramwell said that the discovery of magnetism is an important advance in theoretical physics. Thus, it has been shown that a magnetic charge can move just like an electric one. However, at least for the time being, it is unlikely that magnetism can replace electricity, as conductivity requires that these crystals be cooled to $-272^{\circ} \mathrm{C}$.

\section{Devices controlled only by hand gestures}

Leap Motion has discovered a product through which we can control different devices through hand gestures.

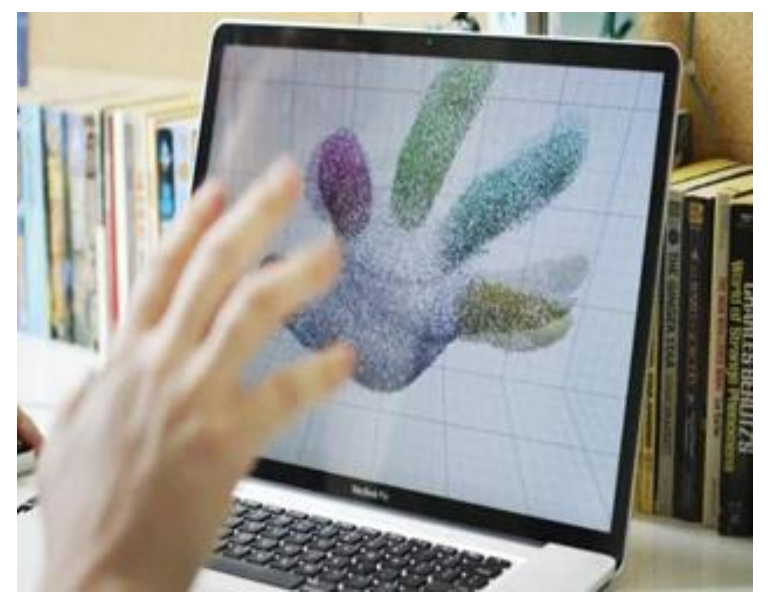

Fig. 2. Control of the device by hand gestures; Source: Technology Review

Unlike a touchscreen interface, Leap does not involve touching or rubbing. The process is not a trivial one, the difference between the two systems being similar to that between conducting a symphony and sketching with chalk on a board the specific movements of the conductor to be performed by the orchestra. Moreover, Leap works in three dimensions. Thanks to this system, we no longer have to "pinch" the screen to enlarge the image. 
Any object can be manipulated by the movement of one or both hands. The system can recognize almost any combination of objects, from the pen to all 10 fingers at once. The new discovery combines the intuition of previous experiences with the possibility to control everything only through fluid movements made in the air.

\section{Conclusions}

Paraphrasing a well-known saying "who does not know his past, does not value his history, does not deserve his future", we can say that a good specialist with a penchant for invention must know the evolution and impact of certain discoveries and inventions that have revolutionized. humanity.

In this context, the training through a specific educational process of future specialists with a call for new, novelty, becomes very important. This ensures favorable conditions for the creation of new inventive "shoots".

The level at which this educational process specific to invention must begin with the primary level, right from kindergarten. Then to continue in the gymnasium, pre-university and especially in the university cycle, including the master's degree and especially during the doctoral internship. $\mathrm{PhD}$ students even have the obligation to carry out inventive and creative activity.

\section{References}

[1] Ioana, A., Noi Descoperiri, Noi Materiale, Noi Tehnologii, Printech, ISBN 978-606-230069-2, Bucureşti, (2013), 9-51.

[2] Chesbrough, H., The Era of Open Innovation. In: Magazine Spring 2003, Research Feature April 15, (2003), 7-15

[3] *** 1000 de evenimente care au modelat lumea, National Geografic, Editura Litera, Bucuresti, (2017), 21-137.

[4] Dan, M.C., Clusterele inovative: o soluţie pentru dezvoltarea economică a României. In: Economie teoretică şi aplicată, Volume XIX (2012), No. 9(574), 3-14.

[5] Casey, M., Hackett, R., The 10 biggest $R \& D$ spenders worldwide, http://fortune.com/2014/11/17/top-10-research-development, (2014) .

[6] Cook, Ph., Strategies for Regional Innovation Systems: Learning Transfer and Applications, United Nations Industrial Development Organization, Vienna, (2003), 11-23.

[7] Cooper, G.R., Stage-Gate Systems: A New Tool for Managing New Products. In: Business Horizons / May-June 1990, (1990), 44-54.

Received: May 01, 2021

Accepted: June 02, 2021 